\title{
The integrated role of multiple healthy weight behaviours on overweight and obesity among adolescents: a cross- sectional study
}

\author{
Sandya Menon ${ }^{1 *}$ (D), Anne Philipneri ${ }^{1}$, Sujitha Ratnasingham ${ }^{1,2}$ and Heather Manson ${ }^{1,3}$
}

\begin{abstract}
Background: This study contributes to the limited number of studies that have explored the impact of not meeting the recommendations for moderate-to-vigorous physical activity, screen time, fruit and vegetable consumption and sleep on overweight and obesity among adolescents.

Methods: A cross-sectional study of data from the 2015 Ontario Student Drug Use and Health Survey (OSDUHS), a provincially representative survey of students in publically funded schools in Ontario, Canada, was conducted. This study included self-reported data from students aged 11-17 years $(n=9866)$. The main outcome variable was overweight or obesity, classified using WHO BMI cut-points. Four independent variables for healthy weight behaviours were examined: (1) moderate-to-vigorous physical activity (MVPA) ( $\geq 60$ mins vs. $<60$ mins everyday over the last seven days); (2) screen time ( $<2 \mathrm{~h}$ daily vs. $\geq 2 \mathrm{~h}$ daily); (3) fruit and vegetable consumption ( $\geq 5$ times/day vs. $<5$ times/day); (4) sleep (adequate based on guidelines vs. inadequate). Covariates included sex, age, Subjective Social Status (SSS), parental education and ethnicity. Binomial and multinomial logistic regression models were fitted to determine whether not meeting the recommendations for healthy weight behaviours was associated with overweight or obesity status.
\end{abstract}

Results: Only 2\% of students in Ontario met the recommendations for all four healthy weight behaviours and 33\% of students did not meet any of the four recommendations. In both the binomial and multinomial models, not meeting the recommendations for MVPA was the only significant healthy weight behaviour associated with both overweight and obesity (AOR: 1.29, 95\% Cl: 1.03-1.62), and solely obesity (AOR: 1.45, 95\% Cl: 1.05-1.99). Males, students with lower SSS ratings, and students with parents with an education of 'High School' or less were also at significantly greater odds of being obese.

Conclusion: Findings from this study show that inadequate levels of MVPA is a critical behavioural predictor of obesity status in adolescents between the ages of 11-17 years, after controlling for differences in screen time, fruit and vegetable consumption, sleep, and demographics. Findings from this study could have implications toward policies and programs targeted at reducing obesity, and increasing the physical activity rates of adolescents.

Keywords: Adolescents, Obesity, Physical Activity, Screen time, Fruit and Vegetable Consumption, Sleep, Recommendations

\footnotetext{
* Correspondence: sandya.menon@oahpp.ca

${ }^{1}$ Public Health Ontario, 480 University Avenue \#300, Toronto, Ontario M5G

1V2, Canada

Full list of author information is available at the end of the article
}

(c) The Author(s). 2019 Open Access This article is distributed under the terms of the Creative Commons Attribution 4.0 International License (http://creativecommons.org/licenses/by/4.0/), which permits unrestricted use, distribution, and reproduction in any medium, provided you give appropriate credit to the original author(s) and the source, provide a link to the Creative Commons license, and indicate if changes were made. The Creative Commons Public Domain Dedication waiver (http://creativecommons.org/publicdomain/zero/1.0/) applies to the data made available in this article, unless otherwise stated. 


\section{Background}

The issue of childhood and adolescent overweight and obesity has consistently been identified as a leading public and global health priority $[1,2]$. The ensuing health risks and chronic conditions that can develop and persist into adulthood have been well-documented, which include but are not limited to, cardiovascular disease, diabetes and various cancers [1]. As of 2016, the global prevalence of overweight and obesity was reported to be over $18 \%$ of all 5-19 year olds, a 14\% increase since 1975 [1]. Within Canada alone, the prevalence of obesity among children and adolescents between the ages of 5-17 years has more than doubled in the last three decades, with nearly onethird of children and adolescents being reported as being either overweight or obese as of 2013 [3, 4]. In consideration of these prominent rates, there is a need to better understand the modifiable risk factors that contribute to increased weight status, in order to better inform policies and interventions aiming to reduce the burden of overweight and obesity among this demographic.

Engagement in select lifestyle behaviours has been shown to impact the likelihood of overweight and obesity in school-aged children and adolescents. Previous studies have shown that moderate-to-vigorous-physical activity (MVPA), screen time and sleep are independently associated with adiposity across varying study designs, including possible dose-response relationships between these modifiable behavioural determinants and adiposity [5-7]. Increased MVPA and longer sleep have been associated with lower adiposity indicators among adolescents, while excessive screen time engagement has shown an increased risk for obesity [5-7].

Fruit and vegetable consumption has also been described as a modifiable behavioural determinant of overweight and obesity, though shown associations in previous studies has been weak and inconsistent among adolescents [8]. However, as fruit and vegetable consumption is commonly considered an indicator for overall diet quality, the implications of dietary behaviours with movement behaviours on weight status should be measured [8,9]. Further examination of the relationships between lifestyle behaviours and body weight could help to better elucidate the strength and consistency of these associations on the weight status of adolescents.

While the isolated relationships between individual healthy weight behaviours and adolescent weight status have been extensively investigated, exploration of the impact of concurrent engagement in more than two healthy weight behaviours is generally under-studied. Within a Canadian context, some studies have examined three of the four aforementioned behaviours (MVPA, screen time and sleep), in light of the release of the 24- $h$ Movement Guidelines for Canadian Children and Youth: An Integration of Physical Activity, Sedentary Behaviour and Sleep, by the Canadian Society for Exercise Physiology [10-12]. Other studies that have examined the associations between all four behaviours (MVPA, screen time, diet and sleep) cannot be applied to a North American context, as their study population would not be representative of North American adolescents [13-15]. Current global and Canadian rates of childhood and adolescent overweight and obesity warrant the need for further research that addresses the influence of lifestyle behaviours on BMI status among this age demographic using an integrated approach.

Through use of a provincially-representative dataset, up-to-date evidence-based national recommendations, and exploration within a Canadian context of four healthy lifestyle behaviours, this study aims to contribute to the limited body of evidence examining the prevalence and integrated role of healthy weight behaviours on overweight and obesity status among adolescents.

\section{Methods \\ Data}

Data for this study were obtained from the 2015 Ontario Student Drug Use and Health Survey (OSDUHS) $(n=10$, 426). The OSDUHS is a repeat-cross-sectional provincial survey that collects information on smoking, alcohol, drug use, and health-related behaviours. Participants are students between grades 7-12 attending publically funded English and French speaking schools in Ontario, Canada. The survey is estimated to represent 92\% [16] of all grade 7-12 students in Ontario and excludes those in private schools, home-schools, institutions for correctional or health reasons, First Nations reserve schools, military bases, and geographically inaccessible areas. Further details regarding the OSDUHS can be found elsewhere [16].

This study restricted the sample only to students aged $11-17$ years in grades $7-12$, to adhere to the age cut-offs used by the nationally established guidelines for MVPA, screen time and sleep [10]. Thus, students aged 18-20 years $(n=560)$ were excluded from this study.

\section{Independent variables}

Student healthy weight behaviours were measured using a self-report questionnaire. Moderate-to-vigorous physical activity (MVPA) was measured using the following question: "On how many of the last 7 days were you physically active for a total of at least 60 minutes on each day? Please add up all the time you spent on any kind of physical activity that increased your heart rate and made you breathe hard some of the time (Some examples are brisk walking, running, rollerblading, biking, dancing, skateboarding, swimming, soccer, basketball, football.) Please include both school and non-school activities." Response options ranged from 0 to 7 days. As 
according to the 2016 Canadian 24-h Movement Guidelines for Children and Youth [10], students who did not report getting at least $60 \mathrm{~min}$ of MVPA each day over the last 7 days were categorized as not having met the guidelines. This questionnaire item has been used in CDC's Youth Risk Behaviour Survey (YRBS) and WHO's Health Behaviour in School-aged Children (HBSC) survey previously, and has been shown to capture responses that were valid and reliable $[17,18]$. For Screen Time, participants were asked "In the last 7 days, about how many hours did you spend: watching TV/movies, playing video/computer games, on a computer/tablet chatting, emailing or surfing the Internet in your free time?" Response options ranged from none to $7 \mathrm{~h}$ or more a day. Students who reported spending more than $2 \mathrm{~h}$ daily in front of a screen were categorized as not having met the guidelines [10]. Students who responded as "Not Sure" were excluded from the analysis. This questionnaire item has also been used in WHO's Health Behaviour in School-aged Children (HBSC) survey previously, and has been shown to capture responses that were valid and reliable [18]. For Fruit and Vegetable Consumption, participants were asked "On an average day, how many times do you eat fruits and vegetables?" with the following response options: [1] 0 times a day; [2] 1 time a day; [3] 2 times a day; [4] 3 times a day; [5] 4 times a day; [6] 5 times a day; [7] 6 or more times a day. This study classified students who did not consume fruits and vegetables at least five times a day as not having met the Association for Public Health Epidemiologists of Ontario (APHEO) Indicator for Vegetable Consumption, which is consistent with cut-offs used in other research [19-21]. For Sleep duration, students were asked "On an average night, how many hours of sleep do you get?" Response options ranged from $4 \mathrm{~h}$ or less, to $10 \mathrm{~h}$ or more. Based on the age-specific cut-offs, students between the ages of 11-13 years who did not report getting 9-11 h of nightly sleep, and students between 14 and 17 years of age who did not report getting $8-10$ h of nightly sleep were categorized as not having met the guidelines [10]. This questionnaire item has been used in CDC's Youth Risk Behaviour Survey (YRBS) and WHO's Health Behaviour in School-aged Children (HBSC) survey previously, and has been shown to capture responses that were valid and reliable $[17,18]$.

\section{Dependent variable}

Students' height and weight were self-reported from a list of given height and weight measurements, provided in inches and centimetres, and pounds and kilograms, respectively. From these measurements, BMI z-scores were derived using the World Health Organization (WHO) growth reference standard [22]. Using the WHO classification, four groups were classified: overweight (z-score $>+1$
Standard Deviation (SD)), obese ( $>+2 \mathrm{SD})$, normal (between +1 and $-2 \mathrm{SD})$ and thinness $(>-2 \mathrm{SD})$. In the initial analysis, these four groups were combined into two groups: (1) overweight and obese, and (2) not overweight and obese. The initial analysis was followed by a secondary analysis, consisting of three groups: (1) obese (2) overweight and (3) not overweight and obese.

\section{Demographic variables}

Age was captured as a continuous measure. For student ethnicity, participants were asked "Which of the following best describes your background (You may choose more than one background)," and provided with 13 ethnicity response options. The following ethnicity groups were created, as according to previously established groupings using OSDUHS data: [23] White, Black, Asian (South Asian, Southeast Asian, Chinese, Japanese, Korean and Filipino) and Other (West Asian or Arab, Aboriginal/First Nations, Latin American, Multi-ethnic). Student-reported paternal and maternal education attainment were combined into a single composite variable with the following groups: (1) University/College Graduate; (2) Some PostSecondary Education, (3) High School Graduate or Less, where data for the parent with the highest education level was used, as done previously [23]. Subjective Social Status (Scale from 1 to 10), measured using the MacArthur Scale of Subjective Social Status (SSS), was also captured as a continuous measure. Parental education attainment and SSS were included simultaneously in models based on previous literature suggesting that each variable measures a different component of social status [23, 24].

\section{Statistical analyses}

Descriptive statistics were computed for all independent, dependent and socio-demographic variables to observe the distribution by BMI status. Associations between the categorical variables and BMI status were examined using second-order design-adjusted Rao-Scott Modified Chi-Squared tests to account for the complex survey design [14]. Scaled Rectangle Diagrams were created in $\mathrm{R}$ to visually describe the prevalence of students meeting recommendations for multiple healthy weight behaviours [25].

Relationships between the four healthy weight behaviours and BMI status in students were explored using multivariable binary and multinomial logistic regression models. The binary logistic regression outcome variable was categorized by students being overweight and obese, and students not being overweight or obese. The multinomial logistic regression outcome variable consisted of three outcome levels: (1) obese, (2) overweight, and (3) not overweight or obese. Regression models were built beginning with the four healthy weight behaviours, followed by adjustment for co-variates. All analyses accounted for 
the complex sampling strategy of OSDUHS and applied the weight, strata, and cluster variables to obtain estimates relative to the target population. Reported values were verified to be meeting the release criteria for OSDUHS (coefficient of variation <33.3). Statistical significance was examined at $\alpha=0.05$ level, unless otherwise noted. All analyses were conducted on SAS V. 9.3 [26].

\section{Results}

The study sample consisted of 9866 students. The majority of students were in high school, with the mean age being 14.9 years. Male students (49\%) represented a slightly lower percentage of the overall population. Students who reported being White represented the largest ethnic group (59\%). As reported by students, the majority of parents were University or College graduates (81\%) (Table 1).

Of students between the ages of $11-17$ years, $20 \%$ were overweight and $10 \%$ were obese. Males were significantly more likely to be overweight and obese compared to females (33.4\% vs. 25.3\%) (Table 1). Students with parents who had completed University or College had a significantly lower percentage of overweight and obesity $(28 \%, p$-value $<0.05)$ relative to those with lower levels of parental educational attainment (Table 1).

More students were observed to be meeting individual healthy weight behaviour recommendations in comparison to multiple recommendations. The greatest percentage of students met the recommendations for screen time (38\%); followed by $34 \%$ for sleep, $22 \%$ for MVPA, and 16\% for fruit and vegetable consumption. The percentage of students meeting recommendations differed across various combinations of healthy weight behaviours (Fig. 1). Onethird (33\%) of students did not meet any of the four recommendations for healthy weight behaviours. Only $2 \%$ of students met the guidelines for all four behaviours (Fig. 1).

Further examination by BMI status showed students who did not meet the guidelines for MVPA (30\% vs. $26 \%)$, screen time (31\% vs. $27 \%)$, and fruit and vegetable consumption (30\% vs. $26 \%$ ) had higher rates of overweight and obesity compared to those who met these recommendations (Table 2). Only 1\% of overweight/ obese students met all four recommendations, which was not statistically significant $(p>0.05)$ from nonoverweight/obese students (2\%) (Fig. 2). Students not meeting any of the four recommendations were five percentage points higher among those who were overweight/obese (37\%), compared to students who were not overweight/obese (32\%) ( $>$ > 0.05).

Not meeting the recommendation for MVPA showed a significant association with overweight and obesity. Students who did not meet the recommendation for MVPA had 1.24 higher odds (95\% CI: $1.06-1.45)$ for

Table 1 Socio-demographic characteristics of OSDUHS students by BMI Status, 2015 ( $n=9866)$

\begin{tabular}{|c|c|c|c|c|c|c|}
\hline \multirow[t]{2}{*}{ Characteristics } & \multicolumn{2}{|c|}{ Overall } & \multicolumn{2}{|c|}{ Overweight/Obese } & \multicolumn{2}{|c|}{ Not Overweight/Obese } \\
\hline & $\%$ & $(95 \% \mathrm{Cl})$ & $\%$ & $(95 \% \mathrm{Cl})$ & $\%$ & $(95 \% \mathrm{Cl})$ \\
\hline \multicolumn{7}{|l|}{ Sex } \\
\hline Male & 48.8 & $(46.2-51.5)$ & $33.4^{* *}$ & $(30.8-36.1)$ & 66.6 & $(63.9-69.2)$ \\
\hline Female & 51.2 & $(48.5-53.8)$ & 25.3 & $(22.8-27.7)$ & 74.8 & $(72.3-77.2)$ \\
\hline \multicolumn{7}{|l|}{ Age (years) } \\
\hline $11-13$ years old & 27.0 & $(24.7-29.3)$ & 30.0 & $(26.2-33.9)$ & 70.0 & $(66.1-73.8)$ \\
\hline $14-17$ years old & 73.0 & (70.7-75.3) & 29.3 & $(27.2-31.3)$ & 70.8 & $(68.7-72.8)$ \\
\hline \multicolumn{7}{|l|}{ Ethnicity } \\
\hline White & 59.0 & $(55.2-62.9)$ & 29.1 & $(26.8-31.3)$ & 70.9 & $(68.7-73.2)$ \\
\hline Black & 5.9 & $(4.7-7.1)$ & 34.4 & $(27.7-41.0)$ & 65.6 & $(59.0-72.3)$ \\
\hline Asian & 19.0 & $(16.0-22.1)$ & 27.9 & $(24.2-31.7)$ & 72.1 & $(68.3-75.8)$ \\
\hline Other & 16.1 & $(14.6-17.6)$ & 30.8 & $(27.4-34.3)$ & 69.2 & $(65.7-72.6)$ \\
\hline \multicolumn{7}{|l|}{ Parental Educational Attainment } \\
\hline High School Graduate or less & 12.7 & $(11.0-14.5)$ & $36.2^{*}$ & $(31.6-40.8)$ & 63.8 & $(59.2-68.4)$ \\
\hline Some Post-Secondary Education & 6.6 & $(5.5-7.7)$ & $32.2^{*}$ & $(24.8-39.6)$ & 67.8 & $(60.4-75.2)$ \\
\hline University/College Graduate & 80.6 & $(78.3-82.9)$ & $28.1^{*}$ & $(25.9-30.2)$ & 71.9 & $(69.8-74.1)$ \\
\hline \multicolumn{7}{|l|}{ Subjective Social Status ${ }^{a}$} \\
\hline$\leq 4$ & 6.1 & $(5.3-7.0)$ & 35.8 & $(28.9-42.7)$ & 64.3 & $(57.3-71.2)$ \\
\hline$\geq 5$ & 93.9 & $(93.0-94.7)$ & 29.0 & $(27.2-30.9)$ & 71.0 & (69.1-72.8) \\
\hline
\end{tabular}

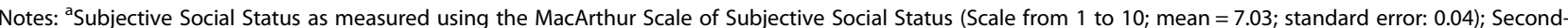
order Rao-Scott Modified Chi Squared tests were conducted to examine differences between each characteristic (i.e., between likelihood of overweight/obesity in males and females) ${ }^{*} P$-value $<0.05 ;{ }^{*} P$-value $<0.01$ 

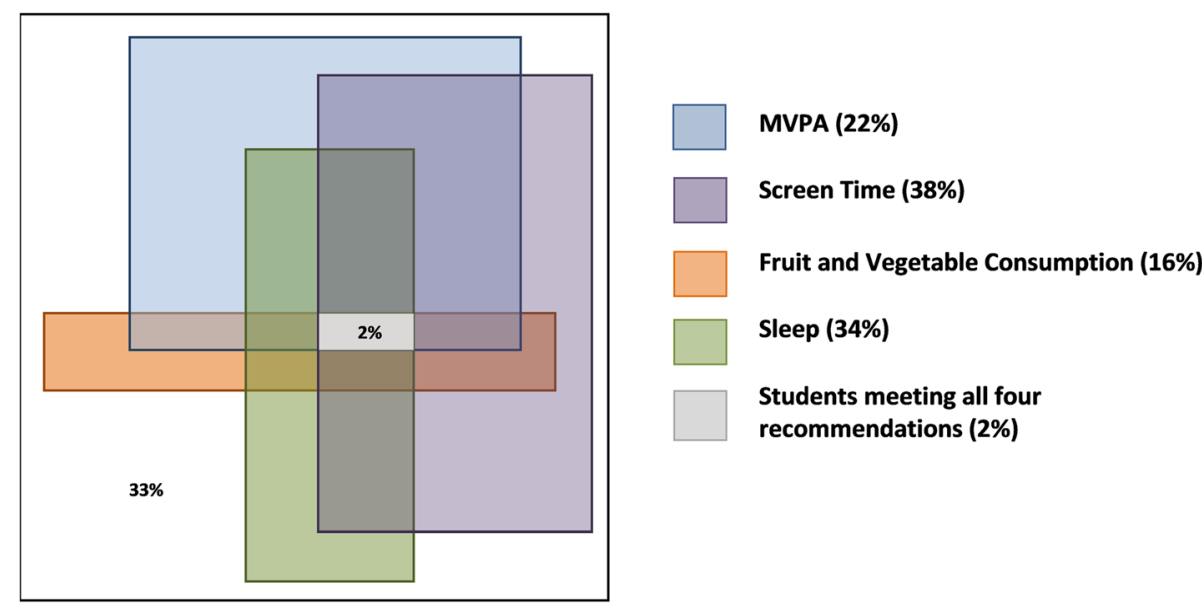

Fruit and Vegetable Consumption (16\%)

Sleep (34\%)

Students meeting all four

recommendations $(2 \%)$

Fig. 1 Percentage of Overall Students in Grades 7-12 Meeting Recommendations for Healthy Weight Behaviours in Ontario, 2015. Note: The size of each rectangle proportionately represents the percentage ofstudents meeting the recommendations for each behaviour; Value in white space represents percentage of students not meeting any of the four healthyweight behaviours." should be underneath the figure

overweight and obesity (Table 2). This difference was not significant after adjusting for the other three healthy weight behaviours (Table 3, Model 1). However, when age, sex, and social status (Model 2); parental education (Model 3); and ethnicity (Model 4) were added sequentially, MVPA showed significant differences by obesity and overweight status. After adjusting for multiple covariates, including age, sex, SSS, parental educational attainment and ethnicity, students who did not meet the recommendations for MVPA showed 1.29 higher odds (95\% CI: 1.03-1.62) for overweight and obesity (Table 3, Model 4). Not meeting recommendations for sleep and fruit and vegetable consumption showed significant associations with overweight and obesity in the unadjusted model (Table 2), but the associations were not significant in the adjusted models (Table 3). Across demographics, it was observed that males showed greater odds of being overweight and obese, while students with parents with an educational attainment of High School education or less showed higher odds of being overweight and obese across all four models. Ethnicity was not a significant predictor of overweight and obesity status among students in this age demographic.

When these outcomes were further divided into separate overweight, obesity, and not overweight and obese statuses, not meeting the recommendations for MVPA continued to be the only behaviour significantly associated with increased odds of being obese in students within this age demographic (Table 4). Students who did

Table 2 Bivariate association between healthy weight behaviors and BMI status

\begin{tabular}{|c|c|c|c|c|c|c|c|c|c|c|}
\hline \multirow{2}{*}{$\begin{array}{l}\text { Healthy Weight } \\
\text { Behaviours }\end{array}$} & \multirow{2}{*}{$\begin{array}{l}\text { Not Obese/Overweight } \\
\%\end{array}$} & \multicolumn{3}{|c|}{ Obese/Overweight } & \multicolumn{3}{|c|}{ Obese } & \multicolumn{3}{|c|}{ Overweight } \\
\hline & & $\%$ & $\mathrm{OR}$ & $95 \% \mathrm{Cl}$ & $\%$ & OR & $95 \% \mathrm{Cl}$ & $\%$ & OR & $95 \% \mathrm{Cl}$ \\
\hline \multicolumn{11}{|l|}{ MVPA } \\
\hline$<60$ mins & 70 & 30 & $1.24^{* *}$ & $(1.06-1.45)$ & 10 & $1.32^{*}$ & $(1.02-1.7)$ & 20 & 1.21 & $(1-1.46)$ \\
\hline$\geq 60$ mins & 74 & 26 & 1.00 & & 8 & 1.00 & & 18 & 1.00 & \\
\hline \multicolumn{11}{|l|}{ Screen Time } \\
\hline$>2 \mathrm{~h}$ & 69 & 31 & $1.17^{*}$ & $(1.03-1.34)$ & 10 & 1.19 & $(0.96-1.49)$ & 20 & 1.16 & $(1-1.35)$ \\
\hline$\leq 2$ hours & 73 & 27 & 1.00 & & 9 & 1.00 & & 18 & 1.00 & \\
\hline \multicolumn{11}{|c|}{ Fruit and Vegetable Consumption } \\
\hline$<5 /$ day & 70 & 30 & $1.23^{*}$ & $(1.04-1.45)$ & 10 & 1.03 & $(0.79-1.35)$ & 20 & $1.35^{* *}$ & $(1.08-1.68)$ \\
\hline$\geq 5$ day & 74 & 26 & 1.00 & & 10 & 1.00 & & 16 & 1.00 & \\
\hline \multicolumn{11}{|l|}{ Sleep } \\
\hline Inadequate ${ }^{a}$ & 70 & 30 & 1.11 & $(0.96-1.27)$ & 10 & 1.08 & $(0.84-1.4)$ & 20 & 1.12 & $(0.95-1.31)$ \\
\hline Adequate $^{\mathrm{b}}$ & 72 & 28 & 1.00 & & 9 & 1.00 & & 19 & 1.00 & \\
\hline
\end{tabular}

Notes: Reference category is not overweight or obese; OR= Odds Ratio; 95\% Cl=95\% Confidence Interval; ${ }^{\mathrm{a}}$ Inadequate sleep = Less than 9-11 h (11-13 year olds),

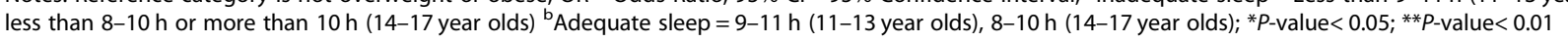




\section{a) Overweight and Obese}

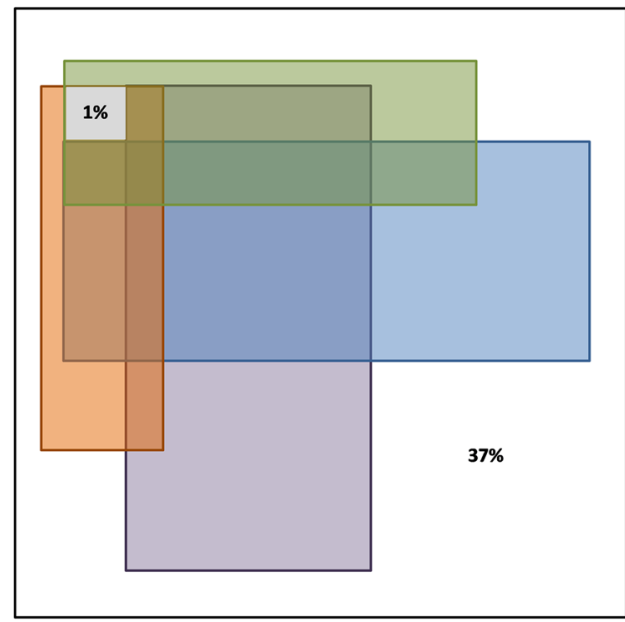

\section{b) Not Overweight or Obese}

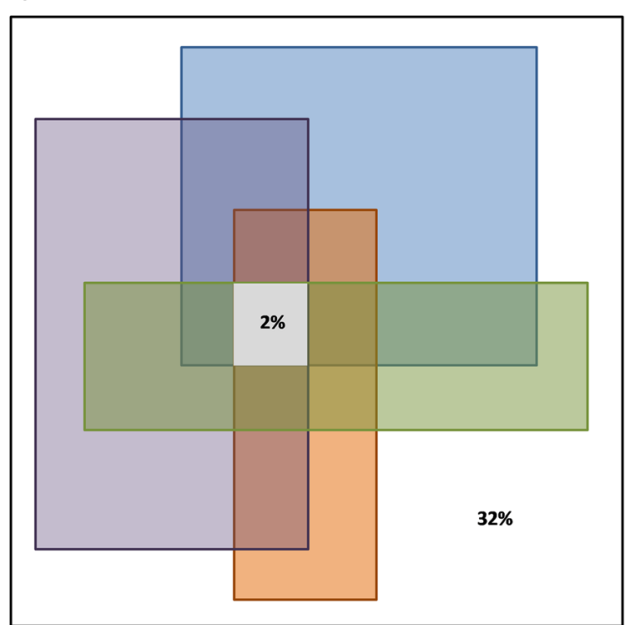

MVPA

Screen Time

Fruit and Vegetable Consumption

Sleep

Students meeting all four

recommendations (1\%)
MVPA

Screen Time

Fruit and Vegetable Consumption

Sleep

Students meeting all four

recommendations (2\%)

Fig. 2 Percentage of Overweight/Obese and Not Overweight/Obese Students in Grades 7-12 Meeting Guidelines for Healthy Weight Behaviours in Ontario, 2015. a Overweight and Obese. b Not overweight and obese. Note: The size of each rectangle proportionately represents the percentage of students meeting the recommendations for each behaviour; Value in white space represents percentage of students not meeting any of the four healthy weight behaviours Note: The size of each rectangle proportionately represents the percentage of students meeting the recommendations for each behaviour; Value in white space represents percentage of students not meeting any of the four healthy weight behaviours

not meet the recommendation for MVPA had 1.32 higher odds (95\% CI: $1.02-1.7$ ) of obesity (Table 2). After controlling for other covariates, the odds for obesity among students who did not meet the guidelines for physical activity increased to 1.45 (95\% CI: 1.05-1.99) compared to students who were not overweight or obese (Table 4). Not meeting recommendations for fruit and vegetable consumption showed higher odds for overweight $(\mathrm{OR}=1.35 ; 95 \% \mathrm{CI}=1.08-1.68)$ (Table 2$)$, however, this was not significant in the multivariable model (Table 4). As observed previously, male students continued to show significantly higher odds of being obese, while students with parents who attended High School or less were at greater odds of being obese. Overall, these findings suggest that not meeting the recommendations for physical activity appears to be a critical behavioral factor in the presence of obesity in 11-17 year old students, even after adjustment for multiple covariates.

\section{Discussion}

This study indicated that the prevalence of students meeting multiple healthy weight recommendations was surprisingly low, and that out of all four of the behaviours examined, not meeting the recommendations for MVPA was the only significant behavioural predictor of obesity status among students within this age demographic.

There is a limited body of research examining the simultaneous role of MVPA, screen time, diet and sleep on 
Table 3 Multivariable logistic regression examining the association between overweight/obesity and healthy weight behaviours with sequential adjustment for demographic characteristics

\begin{tabular}{|c|c|c|c|c|c|c|c|c|}
\hline \multirow[t]{2}{*}{ Characteristics } & \multicolumn{2}{|c|}{ Model 1} & \multicolumn{2}{|c|}{ Model 2} & \multicolumn{2}{|c|}{ Model 3} & \multicolumn{2}{|c|}{ Model 4} \\
\hline & $\overline{A O R}$ & $95 \% \mathrm{Cl}$ & $\overline{A O R}$ & $95 \% \mathrm{Cl}$ & $\overline{A O R}$ & $95 \% \mathrm{Cl}$ & $\overline{\mathrm{AOR}}$ & $95 \% \mathrm{Cl}$ \\
\hline \multicolumn{9}{|l|}{ Healthy Weight Behaviours } \\
\hline \multicolumn{9}{|l|}{ MVPA } \\
\hline$<60$ mins & 1.17 & $(0.98-1.39)$ & $1.22^{*}$ & $(1.02-1.47)$ & $1.27^{*}$ & $(1.04-1.61)$ & $1.29^{*}$ & $(1.03-1.62)$ \\
\hline$\geq 60$ mins & 1.00 & & 1.00 & & 1.00 & & 1.00 & \\
\hline \multicolumn{9}{|l|}{ Screen Time } \\
\hline$>2 \mathrm{~h}$ & 1.14 & $(0.99-1.31)$ & 1.12 & $(0.97-1.30)$ & 1.16 & $(1.02-1.39)$ & 1.15 & $(0.98-1.34)$ \\
\hline$\leq 2$ hours & 1.00 & & 1.00 & & 1.00 & & 1.00 & \\
\hline \multicolumn{9}{|c|}{ Fruit and Vegetable Consumption } \\
\hline$<5 /$ day & 1.16 & $(0.97-1.39)$ & 1.12 & $(0.94-1.34)$ & 1.07 & $(0.91-1.32)$ & 1.08 & $(0.88-1.31)$ \\
\hline$\geq 5$ day & 1.00 & & 1.00 & & 1.00 & & 1.00 & \\
\hline \multicolumn{9}{|l|}{ Sleep } \\
\hline Inadequate ${ }^{a}$ & 1.07 & $(0.92-1.25)$ & 1.10 & $(0.94-1.29)$ & 1.08 & $(0.94-1.31)$ & 1.06 & $(0.91-1.05)$ \\
\hline Adequate $^{b}$ & 1.00 & & 1.00 & & 1.00 & & 1.00 & \\
\hline \multicolumn{9}{|l|}{ Demographics } \\
\hline Age & & & 0.97 & $(0.91-1.03)$ & 0.99 & $(0.93-1.06)$ & 0.98 & $(0.92-1.05)$ \\
\hline \multicolumn{9}{|l|}{ Sex } \\
\hline Male & & & $1.57^{* * *}$ & $(1.33-1.86)$ & $1.65^{* * *}$ & $(1.38-1.97)$ & $1.65^{* * *}$ & $(1.38-1.97)$ \\
\hline Female & & & 1.00 & & 1.00 & & 1.00 & \\
\hline Subjective Social Status $^{c}$ & & & $0.93^{* *}$ & $(0.89-0.98)$ & $0.94^{*}$ & $(0.90-0.99)$ & $0.95^{*}$ & $(0.90-1.00)$ \\
\hline \multicolumn{9}{|c|}{ Parental Educational Attainment } \\
\hline University or College & & & & & 1.00 & & 1.00 & \\
\hline Some Post-Secondary & & & & & 1.11 & $(0.75-1.64)$ & 1.08 & $(0.73-1.60)$ \\
\hline High School or Less & & & & & $1.44^{*}$ & $(1.14-1.83)$ & $1.40^{*}$ & $(1.11-1.78)$ \\
\hline \multicolumn{9}{|l|}{ Ethnicity } \\
\hline White & & & & & & & 1.00 & \\
\hline Black & & & & & & & 1.27 & $(0.89-1.82)$ \\
\hline Asian & & & & & & & 0.94 & $(0.76-1.16)$ \\
\hline Other & & & & & & & 1.05 & $(0.84-1.29)$ \\
\hline \multicolumn{9}{|l|}{ Model Fit Statistics } \\
\hline AlC & \multicolumn{2}{|c|}{$948,941.20$} & \multicolumn{2}{|c|}{$938,443.28$} & \multicolumn{2}{|c|}{$826,815.89$} & \multicolumn{2}{|c|}{$813,784.76$} \\
\hline $\mathrm{BIC}$ & \multicolumn{2}{|c|}{$949,848.38$} & \multicolumn{2}{|c|}{$938,450.34$} & \multicolumn{2}{|c|}{$826,822.82$} & \multicolumn{2}{|c|}{$813,791.66$} \\
\hline $2 \log L$ & \multicolumn{2}{|c|}{$948,939.20$} & \multicolumn{2}{|c|}{$938,441.28$} & \multicolumn{2}{|c|}{$826,813.89$} & \multicolumn{2}{|c|}{$813,782.76$} \\
\hline
\end{tabular}

Notes: Reference category for obese and overweight is not overweight or obese; $\mathrm{AOR}=$ Adjusted Odds Ratio; $95 \% \mathrm{Cl}=95 \% \mathrm{Confidence} \mathrm{Interval}{ }^{\mathrm{a}}$ Inadequate sleep = Less than $9-11 \mathrm{~h}$ (11-13 year olds), less than 8-10 $\mathrm{h}$ or more than $10 \mathrm{~h}$ (14-17 year olds);i ${ }^{\mathrm{b}}$ Adequate sleep $=9-11 \mathrm{~h}(11-13$ year olds), $8-10 \mathrm{~h}(14-17$ year olds); 'Subjective Social Status, as measured using the MacArthur Scale of Subjective Social Status (Scale from 1 to 10); *P-value<0.05;

**P-value $<0.01 ; * * *$-value $<0.001$

adolescent weight status, and lacking consistency in the measurement of these behaviours at the international level [13-15]. To the authors' knowledge, this is the first study to examine the prevalence of students meeting the recommendations for these four healthy weight behaviours in a Canadian context. Consequently, the observed prevalence rates of students meeting healthy weight behaviour recommendations could not be compared with other reported Canadian findings, as no other study has examined all four of these rates at the national level. However, existing studies have evaluated the combined impact of three out of the four behaviours addressed in the current study [11, 27-34]. Notably, Roman-Vinas et al. investigated the global prevalence of 9-11 year olds meeting the recommendations for MVPA, screen time and sleep, and observed that only $7 \%$ of children 
Table 4 Multinomial logistic regression examining association between healthy weight behaviours and obesity overweight status by age, sex, SSS, parental educational attainment and ethnicity

\begin{tabular}{llll}
\hline Characteristics & & Overweight \\
\cline { 2 - 2 } & AOR $95 \% \mathrm{Cl}$ & & AOR $95 \% \mathrm{Cl}$ \\
\hline
\end{tabular}

Healthy weight behaviours

MVPA

$\begin{array}{lllll}<60 \text { mins } & 1.45^{*} & (1.05-1.99) & 1.23 & (0.96-1.58) \\ \geq 60 \text { mins } & 1.00 & & 1.00 & \end{array}$

Screen Time

\begin{tabular}{|c|c|c|c|c|}
\hline$>2 \mathrm{~h}$ & 1.14 & $(0.88-1.47)$ & 1.15 & $(0.98-1.36)$ \\
\hline$\leq 2$ hours & 1.00 & & 1.00 & \\
\hline
\end{tabular}

Fruit and vegetable consumption

\begin{tabular}{|c|c|c|c|c|}
\hline$<$ 5/day & 0.87 & $(0.66-1.15)$ & 1.20 & $(0.93-1.56)$ \\
\hline$\geq 5$ day & 1.00 & & 1.00 & \\
\hline \multicolumn{5}{|l|}{ Sleep } \\
\hline Inadequate $^{a}$ & 1.08 & $(0.79-1.47)$ & 1.06 & $(0.90-1.25)$ \\
\hline Adequate $^{b}$ & 1.00 & & 1.00 & \\
\hline \multicolumn{5}{|l|}{ Demographics } \\
\hline Age & 0.96 & $(0.87-1.06)$ & 0.99 & $(0.92-1.07)$ \\
\hline \multicolumn{5}{|l|}{ Sex } \\
\hline Male & $2.08^{* * *}$ & $(1.58-2.74)$ & $1.47^{* * *}$ & $(1.20-1.82)$ \\
\hline Female & 1.00 & & 1.00 & \\
\hline Subjective Social Status ${ }^{c}$ & $0.90^{* *}$ & $(0.83-0.97)$ & 0.97 & $(0.92-1.03)$ \\
\hline \multicolumn{5}{|c|}{ Parental Educational Attainment } \\
\hline High School or Less & $1.93^{* * *}$ & $(1.38-2.71)$ & 1.16 & $(0.91-1.50)$ \\
\hline Some Post-Secondary & 1.12 & $(0.69-1.83)$ & 1.06 & $(0.67-1.68)$ \\
\hline University or College & 1.00 & & 1.00 & \\
\hline \multicolumn{5}{|l|}{ Ethnicity } \\
\hline White & 1.00 & & 1.00 & \\
\hline Black & 1.58 & $(0.89-2.82)$ & 1.12 & $(0.79-1.58)$ \\
\hline Asian & 0.97 & $(0.70-1.35)$ & 0.92 & $(0.75-1.13)$ \\
\hline Other & 1.04 & $(0.74-1.47)$ & 1.05 & $(0.83-1.32)$ \\
\hline
\end{tabular}

Model Fit Statistics

AIC

$1,066,222.90$

$\mathrm{BIC}$

$1,066,236.70$

$2 \log \mathrm{L}$

$1,066,218.90$

Notes: Reference category for obese and overweight is not overweight or obese; $\mathrm{AOR}=$ Adjusted Odds Ratio; $95 \% \mathrm{Cl}=95 \%$ Confidence Interval; anadequate sleep $=$ Less than $9-11 \mathrm{~h}(11-13$ year olds), less than $8-10 \mathrm{~h}$ or more than $10 \mathrm{~h}$ ( $14-17$ year olds) ${ }^{\mathrm{b}}$ Adequate sleep $=9-11 \mathrm{~h}$ (11-13 year olds), 8-10 h (14-17 year olds); 'Subjective Social Status, as measured using the MacArthur Scale of Subjective Social Status (Scale from 1 to $10 * P$-value $<0.05$; ${ }^{* *} P$-value $<0.01 ;{ }^{* * *} P$-value $<0.001$

worldwide are adhering to all three, which is comparable to the results observed in the current study (4\%, not shown in Fig. 1) [28]. Carson et al. also explored the impact of these three behaviours among 6-17 year-old Canadian children and adolescents, observing 17\% of participants to be complying with the same three guidelines [11]. While our results are most comparable to the global prevalence of children meeting recommendations for MVPA, screen time and sleep, differences between our findings and other Canadian research is striking. However, these discrepancies could be attributed to differences in study population age (ie. Roman-Vinas et al., 2016 and Carson et al., 2017 included participants younger than eleven years of age), and methodology and measurement, such as self-report vs. objective/accelerometry-based measures for MVPA, sleep duration, and anthropometry measurements $[11,28]$.

In this study of adolescents, not meeting recommendations for MVPA appeared to have the strongest association for obesity, when compared with other lifestyle behaviours. The isolated relationship between MVPA and healthy weight status has been well-documented in the literature, attributable to the direct physiological impact of adequate physical activity on adiposity, which promotes the establishment of an energy balance between consumed and expended calories [35-37]. Existing studies have presented findings comparable with the results from this study [28-30, 38]. Wilkie et al. studied possible associations between not meeting healthy weight recommendations for all four healthy weight behaviours and BMI z-score in a UK-based sample of adolescents between the ages of 9-11, noting that participants who did not meet the recommendations for physical activity had a significantly higher BMI $\mathrm{z}$-score compared to those who were classified as adequately active [14]. The study by Roman-Vinas et al., which evaluated a sample that included Canadian participants, noted that 9-11 year olds that did not meet the MVPA guideline showed the highest odds for obesity, when compared to not meeting guidelines for screen time and sleep [28]. Laurson et al. also found an analogous relationship between MVPA and obesity, observing that not meeting the MVPA guideline was the only behaviour that resulted in an increased likelihood of being obese in a sample of American adolescents in grades 9-12, regardless of whether screen time or sleep guidelines were adhered to [29].They also found that adolescents not meeting the recommendations for physical activity were at an increased odds of not meeting (or exceeding) the recommendations for screen time $[29,38]$. This finding presents a possible explanation for the observed association in this study between not meeting the recommendation for MVPA and obesity status in our study, as adolescents may be using time that could otherwise be spent being physically active to engage in behaviours with negative impacts on weight status, such as excessive screen time and consumption of sugar-sweetened foods and beverages. While there is considerable evidence to suggest MVPA as being 
the strongest behavioural determinant of adiposity, these findings support the notion that lifestyle behaviours synergistically contribute to BMI status, and reinforce the need to study the relationships between these behaviours and weight status concurrently $[39,40]$.

Our findings also indicated a number of sociodemographic factors to be significantly predictive of obesity status in adolescents between the ages of 11-17 years. Males had increased odds of being obese in comparison to females within this age demographic, a tendency in NorthAmerican adolescents that has been previously acknowledged within the literature [4, 41, 42]. Differences in gender-specific biology, genetics, and behaviours such as self-reporting are possible sources for these discrepancies, and are further compounded by subjective cultural, environmental and socio-economic circumstances [42]. Findings from our study also showed adolescents to be at greater odds of being obese based on lower SSS ratings and lower parental education levels. A study exploring the associations between SSS ratings and overweight and obesity noted similar results, demonstrating the potential impacts of subjective perceptions of society on health outcomes among school-aged adolescents [24]. Our finding that lower parental education levels (used as a proxy for socio-economic status (SES)) were significantly predictive of greater odds of obesity was also consistent with previous research conducted among US and Canadian children and adolescents between the ages of 10-17 years, which have identified an inverse relationship between household SES and obesity in higher economic status countries [43, 44]. In examining the associations between socio-demographic factors and obesity among adolescents, there currently exists a literature gap in the body of research that has examined this relationship in conjunction with healthy weight behaviours. Our research is one of few to have not only examined socio-demographic characteristics as individual covariates, but to have addressed the role of sex, child's perceived social status and parental educational attainment on obesity status in a study primarily focused on the interactive impact of multiple healthy weight behaviours. While this level of analysis may facilitate a more comprehensive understanding of the complexities in the behavioural and social interactions affecting adolescent overweight and obesity, further research examining the joint effects of lifestyle and environmental factors is necessary in order to address the true role of social disparities on weight status among adolescents [43].

\section{Limitations}

Several limitations should be taken into consideration when interpreting the findings of this study. The crosssectional nature of this study prevents us from making any causal or reverse-causal inferences from the study results, as the temporality of overweight or obese weight status cannot be established. All responses in OSDUHS are self-reported, leading to potential recall and social desirability bias [16]. A study comparing the differences in self-reported vs. direct height and weight measurements in Canadians noted self-reported height to be typically greater than measured height, while self-reported weight was lower than measured weight [45]; consequently, self-reported rates of overweight and obesity were lower than rates provided by direct measures. This suggests that the rates provided in this study may underestimate the true magnitude of overweight and obesity in Ontario's adolescents. Differences in self-reporting by sex have generally been minimal, though a few studies have shown a greater tendency for misreporting height and weight in overweight and obese female adolescents [45-49]. Studies examining the validity of self-reported health behaviour measures have noted that adolescents commonly over-report their engagement in the study's healthy weight behaviours [50-53]. While self-report surveys function as a useful tool for the purposes of behavioural trend surveillance, direct measures for capturing these behaviours would allow for more accurate measurement of compliance to Canadian recommendations [50-53]. In addition, the self-report measure used for fruit and vegetable consumption determined fruit and vegetable consumption based on frequency of daily consumption, and not relative to servings consumed. Therefore, phrasing of the survey question, in addition to the range of response categories offered to study participants in the survey, inhibited any comparisons to Health Canada's Canada Food Guide guidelines. However, the cut-off for fruit and vegetable consumption used in this study has been used in previous literature, and is comparable to thresholds used world-wide [20, 21, 54]. Findings from this study cannot be applied to Ontario students who were excluded from the 2015 OSDUHS sample, including students enrolled in private schools, First Nations schools on reserve, military bases, in the remote northern region of Ontario and those in geographically inaccessible areas [16]. All students excluded from the OSDUHS sample collectively represent approximately $8 \%$ of the Ontario student population in grades 7-12.

\section{Conclusions}

This study highlights the importance of exploring overweight and obesity across multiple lifestyle behaviours and socio-demographic characteristics, in order to accurately account for the collective influence of these factors on adolescent weight status. According to our findings, onethird of Ontario adolescents aged 11-17 years are not meeting any of the four examined healthy weight 
behaviour recommendations. The implications of this alarming statistic should be considered promptly by stakeholders and decision-makers developing programs and policies to improve health outcomes among Ontarians within this age bracket. The finding that fruit and vegetable consumption was the recommendation least complied with by adolescents also indicates that more research inclusive of this behaviour, alongside other healthy lifestyle behaviours, is warranted. Our study also noted that MVPA was consistently the sole predictor of overweight and obesity status among these four behaviours, suggesting that this behaviour may be the most important behavioural target for interventions aiming to prevent and manage obesity in adolescents. Further research examining the combined impact of these lifestyle behaviours on overweight and obesity status is necessary in order to comprehensively address this public health issue.

\section{Abbreviations \\ AOR: Adjusted odds ratio; APHEO: Association of Public Health Epidemiologists of Ontario; BMI: Body mass index; Cl: Confidence interval; MVPA: Moderate-to-vigorous physical activity; OSDUHS: Ontario student drug-use and health survey; SD: Standard deviation; SSS: Subjective social status; WHO: World Health Organization}

\section{Acknowledgements}

"The data used in this publication came from the Ontario Student Drug Use and Health Survey conducted by the Centre for Addiction and Mental Health and administered by the Institute for Social Research, York University. Its contents and interpretation are solely the responsibility of the author and do not necessarily represent the official view of the Centre for Addiction and Mental Health." Findings from this study have been presented at the 2017 Canadian Society for Epidemiology and Biostatistics Biennial Conference (Banff, Canada) on May 30-June 2, 2017, and the 16th annual scientific meeting of the International Society of Behavioural Nutrition and Physical Activity (Victoria, Canada) on June 7-10, 2017.

The authors would like to acknowledge Public Health Ontario's Research \& Ethics Services for their approval of this study. They would also like to thank Dr. Robert Mann and Dr. Hayley Hamilton for sharing the 2015 OSDUHS data with Public Health Ontario, and for their support through the research process.

\section{Authors' contributions}

HM authorized an agreement with CAMH to purchase access to the 2015 OSDUHS data. This study was conceived by AP and SR. Statistical analysis and interpretations of findings was completed by SM, and AP. SM conducted the literature review and prepared the manuscript. All authors contributed to planning the study design, methodology, reviewed the manuscript for intellectual content and approved the final manuscript.

\section{Funding}

The study design, data analysis and interpretation, and manuscript writing were funded by Public Health Ontario. Data collection for the Ontario Student Drug Use and Health Survey, a Centre for Addiction and Mental Health initiative, was funded, in part, by the Ontario Ministry of Health and Long-Term Care.

\section{Availability of data and materials}

The data that support the findings of this study are available from the Centre for Addiction and Mental Health but restrictions apply to the availability of these data, which were used under license for the current study, and so are not publicly available. Data are however available from the authors upon reasonable request and with permission of $\mathrm{CAMH}$. The 2015 OSDUHS data is stored at the Centre for Addiction and Mental Health $(\mathrm{CAMH})$ as well as Public Health Ontario. For access, please contact the corresponding author.

\section{Ethics approval and consent to participate}

This study has been approved by the Public Health Ontario Ethics Review Board (File no.2016-034.01). The need for informed consent to participate was waived due to the retrospective nature of this study.

\section{Consent for publication}

Not applicable.

\section{Competing interests}

The authors of this study declare that they have no competing interests.

\section{Author details}

${ }^{1}$ Public Health Ontario, 480 University Avenue \#300, Toronto, Ontario M5G 1V2, Canada. ${ }^{2}$ Institute for Clinical Evaluative Sciences, 2075 Bayview Ave, Toronto, ON M4N 3M5, Canada. ${ }^{3}$ Dalla Lana School of Public Health, University of Toronto, 480 University Avenue \#300, Toronto, Ontario M5G 1V2, Canada.

Received: 5 December 2018 Accepted: 17 May 2019

Published online: 22 August 2019

\section{References}

1. World Health Organization. World Health Organization fact sheet N311: obesity and overweight. 2018. http://www.who.int/news-room/fact-sheets/ detail/obesity-and-overweight. Accessed 1 Oct 2018.

2. Ng M, Fleming T, Robinson M, Thomson B, Graetz N, Margono C, Mullany EC, Biryukov S, Abbafati C, Abera SF, Abraham JP. Global, regional, and national prevalence of overweight and obesity in children and adults during 1980-2013: a systematic analysis for the global burden of disease study 2013. Lancet. 2014;384(9945):766-81. https://doi.org/10.1016/S01406736(14)60460-8.

3. Ontario Agency for Health Protection and Promotion (Public Health Ontario). Addressing obesity in children and youth: evidence to guide action for Ontario. Toronto: Queen's Printer for Ontario; 2013. https://www. publichealthontario.ca/en/eRepository/Addressing_Obesity_Children_ Youth_Sept2013.pdf. Accessed 1 Apr 2017

4. Roberts KC, Shields M, de Groh M, Aziz A, Gilbert JA. Overweight and obesity in children and adolescents: results from the 2009 to 2011 Canadian health measures survey. Health Rep. 2012;23(3):37-41.

5. Janssen I, LeBlanc AG. Systematic review of the health benefits of physical activity and fitness in school-aged children and youth. Int J Behav Nutr Phys Act. 2010;7(1):40. https://doi.org/10.1186/1479-5868-7-40.

6. Chaput JP, Gray CE, Poitras VJ, Carson V, Gruber R, Olds T, Weiss SK, Connor Gorber S, Kho ME, Sampson M, Belanger K. Systematic review of the relationships between sleep duration and health indicators in school-aged children and youth. Appl Physiol Nutr Metab. 2016;41(6):S266-82.

7. Tremblay MS, LeBlanc AG, Kho ME, Saunders TJ, Larouche R, Colley RC, Goldfield G, Gorber SC. Systematic review of sedentary behaviour and health indicators in school-aged children and youth. Int J Behav Nutr Phys Act. 2011;8(1):98. https://doi.org/10.1186/1479-5868-8-98

8. Ledoux TA, Hingle MD, Baranowski T. Relationship of fruit and vegetable intake with adiposity: a systematic review. Obes Rev. 2011;12(5):e143-50. https://doi.org/10.1111/j.1467-789X.2010.00786.x.

9. Garriguet D. Diet quality in Canada. Health Rep. 2009;20(3):1-12.

10. Tremblay M, Carson V, Chaput J, Connor Gorber S, Dinh T, Duggan M, Faulkner G, Gray C, Guber R, Janson K, Janssen I. Canadian 24-hour movement guidelines for children and youth: an integration of physical activity, sedentary behaviour and sleep. Appl Physiol Nutr Metab. 2016; 41(6):S311-27.

11. Carson V, Chaput JP, Janssen I, Tremblay MS. Health associations with meeting new 24-hour movement guidelines for Canadian children and youth. Prev Med. 2017;95:7-13. https://doi.org/10.1016/j.ypmed.2016.12.005.

12. Roberts KC, Yao X, Carson V, Chaput JP, Janssen I, Tremblay MS. Meeting the Canadian 24-hour movement guidelines for children and youth. Health Rep. 2017 Oct 1;28(10):3-7.

13. Sun Y, Sekine M, Kagamimori S. Lifestyle and overweight among Japanese adolescents: the Toyama birth cohort study. J Epidemiol. 2009;19(6):303-10. https://doi.org/10.2188/jea.JE20080095.

14. Wilkie H, Standage M, Gillison F, Cumming S, Katzmarzyk P. Multiple lifestyle behaviours and overweight and obesity among children aged 9-11 years: 
results from the UK site of the international study of childhood obesity, lifestyle and the environment. BMJO. 2016;6(2):e010677.

15. Pérez-Rodrigo C, Gil Á, González-Gross M, Ortega RM, Serra-Majem L, VarelaMoreiras G, Aranceta-Bartrina J. Clustering of dietary patterns, lifestyles, and overweight among Spanish children and adolescents in the ANIBES study. Nutrients. 2015:8(1):11.

16. Boak A, Hamilton A, Adlaf EM, Henderson JL, Mann RE. The mental health and well-being of Ontario students, 1991-2015: detailed OSDUHS findings (CAMH research document series no.43). Centre for Addiction and Mental Health: Toronto; 2016. https://www.camh.ca/-/media/files/pdf-\%2D-osduhs/themental-health-and-well-being-of-ontario-students-1991-2015-\%2D-detailedosduhs-findings.pdf?la=en\&hash= 59BFD5B17408AAEE0E837E01048088ED51E558B2.

17. U.S. Centers for Disease Control and Prevention. Youth Risk Behavior Surveillance System (YRBSS). http://www.cdc.gov/yrbs. Accessed 5 Mar 2019.

18. World Health Organization. Health Behaviors in School Children (HBSC). http://www.hbsc.org/. Accessed 5 Mar 2019.

19. APHEO - 5D Vegetable and Fruit Consumption, 2010. http://core.apheo.ca/ index.php?pid=128. Accessed 18 Jul 2017.

20. Serdula M, Gillespie C, Kettel-Khan L, Farris R, Seymour J, Denny C. Trends in fruit and vegetable consumption among adults in the United States: Behavioural risk factor surveillance system, 1994-2000. Am J Public Health. 2004;94(6):1014-8. https://doi.org/10.2105/AJPH.94.6.1014.

21. Pearson N, Atkin A, Biddle S, Gorely T, Edwardson C. Patterns of adolescent physical activity and dietary behaviours. Int J Behav Nutr Phys Act. 2009;6(1): 45. https://doi.org/10.1186/1479-5868-6-45.

22. Onis MD, Onyango AW, Borghi E, Siyam A, Nishida C, Siekmann J. Development of a WHO growth reference for school-aged children and adolescents. Bull World Health Organ. 2007;85:660-7. https://doi.org/10.2471/BLT.07.043497.

23. Hamilton $\mathrm{H}$, van der Maas M, Boak A, Mann R. Subjective social status, immigrant generation, and cannabis and alcohol use among adolescents. J Youth Adol. 2014;43(7):1163-75. https://doi.org/10.1007/s10964-013-0054-y.

24. Elizabeth $\mathrm{G}$, et al. Adolescents' perceptions of social status: development and evaluation of a new indicator. Pediatrics. 2001;108(2):e31.

25. R Core Team. R: A language and environment for statistical computing. Vienna: R Foundation for Statistical Computing; 2016. ISBN 3-900051-07-0, URL: http://www.R-project.org/

26. SAS Institute Inc. Base SAS ${ }^{\circledR} 9.3$ Procedures Guide. Cary: SAS Institute Inc:; 2016.

27. Leech RM, McNaughton SA, Timperio A. The clustering of diet, physical activity and sedentary behavior in children and adolescents: a review. Int J Behav Nutr Phys Act. 2014;11(1):4. https://doi.org/10.1186/1479-5868-11-4.

28. Roman-Viñas B, Chaput JP, Katzmarzyk PT, Fogelholm M, Lambert EV, Maher C, Maia J, Olds T, Onywera V, Sarmiento OL, Standage M. Proportion of children meeting recommendations for 24-hour movement guidelines and associations with adiposity in a 12-country study. Int J Behav Nutr Phys Act. 2016;13(1):123.

29. Laurson KR, Lee JA, Eisenmann JC. The cumulative impact of physical activity, sleep duration, and television time on adolescent obesity: 2011 youth risk behavior survey. J Phys Act Health. 2015;12(3):355-60. https://doi. org/10.1123/jpah.2013-0402.

30. Laurson KR, Lee JA, Gentile DA, Walsh DA, Eisenmann JC. Concurrent associations between physical activity, screen time, and sleep duration with childhood obesity. ISRN Obes. 2014;2014. https://doi.org/10.1155/2014/ 204540.

31. Martinez-Gomez D, Moreno LA, Romeo J, Rey-López JP, Castillo R, Cabero MJ, Vicente-Rodriguez G, Gutiérrez A, Veiga OL, Marcos A, AVENA Study Group. Combined influence of lifestyle risk factors on body fat in Spanish adolescents-the Avena study. Obesity Facts. 2011; 4(2):105-11. https://doi.org/10.1159/000327686.

32. Chaput JP, Saunders TJ, Carson V. Interactions between sleep, movement and other non-movement behaviours in the pathogenesis of childhood obesity. Obes Rev. 2017;18(S1):7-14.

33. Thasanasuwan W, Srichan W, Kijboonchoo K, Yamborisut U, Wimonpeerapattana W, Rojroongwasinkul N, Khouw IT, Deurenberg P. Low sleeping time, high TV viewing time, and physical inactivity in school are risk factors for obesity in pre-adolescent Thai children. J Med Assoc Thai. 2016:99(3):314-21.

34. Chaput JP, Leduc G, Boyer C, Belanger P, LeBlanc AG, Borghese MM, Tremblay MS. Objectively measured physical activity, sedentary time and sleep duration: independent and combined associations with adiposity in Canadian children. Nutr Diabetes. 2014:4(6):e117. https://doi. org/10.1038/nutd.2014.14.
35. Patrick K, Norman GJ, Calfas KJ, Sallis JF, Zabinski MF, Rupp J, Cella J. Diet, physical activity, and sedentary behaviors as risk factors for overweight in adolescence. Arc Pediatr Adolesc Med. 2004;158(4):385-90. https://doi.org/ 10.1001/archpedi.158.4.385

36. Janssen I, Le Blanc AG. Systematic review of the health benefits of physical activity and fitness in school-aged children and youth. Int J Behav Nutr Phys Act. 2010;7(1):40. https://doi.org/10.1186/1479-5868-7-40.

37. Janssen I, Katzmarzyk PT, Boyce WF, King MA, Pickett W. Overweight and obesity in Canadian adolescents and their associations with dietary habits and physical activity patterns. J Adol Health. 2004;35(5):360-7. https://doi. org/10.1016/S1054-139X(04)00058-8.

38. van der Sluis ME, Lien N, Twisk JW, Steenhuis $\mathrm{H}$, Bere E, Klepp KI, Wind M. Longitudinal associations of energy balance-related behaviours and crosssectional associations of clusters and body mass index in Norwegian adolescents. Public Health Nutr. 2010;13(10):1716-21.

39. Chaput JP, Lambert M, Mathieu ME, Tremblay MS, O'loughlin J, Tremblay A. Physical activity vs. sedentary time: independent associations with adiposity in children. Pediatr obes. 2012;7(3):251-8. https://doi.org/10.1111/j.2047-6310.2011.00028.x

40. Marques A, Minderico C, Martins S, Palmeira A, Ekelund U, Sardinha LB. Cross-sectional and prospective associations between moderate to vigorous physical activity and sedentary time with adiposity in children. Int J of Obes. 2016;40(1):28. https://doi.org/10.1038/ijo.2015.168.

41. Ogden CL, Carroll MD, Kit BK, Flegal KM. Prevalence of obesity and trends in body mass index among US children and adolescents, 1999-2010. JAMA. 2012;307(5):483-90. https://doi.org/10.1001/jama.2012.40.

42. Sweeting $\mathrm{H}$. Gendered dimensions of obesity in childhood and adolescence. Nutr J. 2008. https://doi.org/10.1186/1475-2891-7-1.

43. Singh GK, Kogan MD, Van Dyck PC, Siahpush M. Racial/ethnic, socioeconomic, and behavioral determinants of childhood and adolescent obesity in the United States: analyzing independent and joint associations. Ann Epidemiol. 2008;18(9):682-95. https://doi.org/10.1016/j.annepidem.2008.05.001.

44. Muthuri SK, Onywera VO, Tremblay MS, Broyles ST, Chaput JP, Fogelholm M, Hu G, Kuriyan R, Kurpad A, Lambert EV, Maher C. Relationships between parental education and overweight with childhood overweight and physical activity in 9-11 year old children: results from a 12-country study. PLoS One. 2016 Aug 24;11(8):e0147746.

45. Shields M, Gorber SC, Tremblay MS. Estimates of obesity based on selfreport versus direct measures. Health Rep. 2008;19(2):61.

46. Ontario Agency for Health Protection and Promotion (Public Health Ontario), Singh T, Tyler I. Evidence Brief: Self report versus direct measures of height, weight, and BMI in 0-18 year olds: a synthesis of primary studies from 2004-2014. Toronto: Queen's Printer for Ontario; 2015. https://www. publichealthontario.ca/en/eRepository/Self_reports_BMI_Youth.pdf. Accessed 1 Aug 2016

47. Yoshitake N, Okuda M, Sasaki S, Kunitsugu I, Hobara T. Validity of selfreported body mass index of Japanese children and adolescents. Pediatr Int. 2012;54(3):397-401. https://doi.org/10.1111/j.1442-200X. 2011.03541.x

48. Linhart $Y$, Romano-Zelekha O, Shohat T. Validity of self-reported weight and height among 13-14 year old schoolchildren in Israel. Isr Med Assoc J. 2010; 12(10):603-5.

49. Ambrosi-Randić N, Bulian AP. Self-reported versus measured weight and height by adolescent girls: a Croatian sample. Percept Mot Skills. 2007; 104(1):79-82.

50. Garriguet D, Colley RC. A comparison of self-reported leisure-time physical activity and measured moderate-to-vigorous physical activity in adolescents and adults. Health Rep. 2014;25(7):3.

51. Lubans DR, Hesketh K, Cliff DP, Barnett LM, Salmon J, Dollman J, Morgan PJ, Hills AP, Hardy LL. A systematic review of the validity and reliability of sedentary behaviour measures used with children and adolescents. Obes Rev. 2011;12(10):781-99. https://doi.org/10.1111/j.1467-789X.2011. 00896.x.

52. Eaton DK, Olsen EO, Brener ND, Scanlon KS, Kim SA, Demissie Z, Yaroch AL. A comparison of fruit and vegetable intake estimates from three survey question sets to estimates from 24-hour dietary recall interviews. J Acad Nutr Diet. 2013;113(9):1165-74.

53. Lauderdale DS, Knutson KL, Yan LL, Liu K, Rathouz PJ. Sleep duration: how well do self-reports reflect objective measures? The CARDIA sleep study. Epidemiol. 2008;19(6):838. https://doi.org/10.1097/EDE. Ob013e318187a7b0 
54. Serdula MK, Gillespie C, Kettel-Khan L, Farris R, Seymour J, Denny C. Trends in fruit and vegetable consumption among adults in the United States: behavioral risk factor surveillance system, 1994-2000. Am J Public Health. 2004;94(6):1014-8. https://doi.org/10.2105/AJPH.94.6.1014.

\section{Publisher's Note}

Springer Nature remains neutral with regard to jurisdictional claims in published maps and institutional affiliations.

Ready to submit your research? Choose BMC and benefit from:

- fast, convenient online submission

- thorough peer review by experienced researchers in your field

- rapid publication on acceptance

- support for research data, including large and complex data types

- gold Open Access which fosters wider collaboration and increased citations

- maximum visibility for your research: over $100 \mathrm{M}$ website views per year

At BMC, research is always in progress.

Learn more biomedcentral.com/submissions 